\title{
The Ethnomathematics Practices of Eskaya Tribe
}

\author{
Fe R. Janiola, PhD ${ }^{\mathrm{a}}$, Maria Salud M. De Los Santos ${ }^{\mathrm{b}}$ \\ ${ }^{a}$ College of Arts and Sciences, Holy Name University, Tagbilaran City, Bohol, Philippines \\ ${ }^{\mathrm{b}}$ Cebu Technological University-Main, Naga Campus, Cebu City, Philippines \\ afjaniola@gmail.com, bsimplymariz@gmail.com
}

Article History: Received: 10 November 2020; Revised 12 January 2021 Accepted: 27 January 2021; Published online: 5 April 2021

\begin{abstract}
This research sought to describe the Ethno-mathematical practices of the Eskaya tribe of Taytay, Duero, Bohol using the ethnographical research design to explore the ethnomathematics practices through the lived experiences of the informants. Employing purposive sampling, selected teachers, parents, and students from the tribe served as the key informants of the study. Data collection took almost a year of observation, lived experiences documentation, and interviews. The study was able to describe some of the ethnomathematical practices of the Eskaya tribe such as the skills and processes of the Eskaya tribe commonly use in their daily life in counting, measuring, ciphering, ordering, classifying, inferring, and modeling patterns. These skills and techniques were used in studying their Eskaya numeration systems such as the Eskaya numbers and numerals, the Eskaya name of the basic shapes and the four fundamental operations, and the use of Eskaya numbers in measuring time, days, and months.
\end{abstract}

Keywords: Eskaya tribe, Ethnomathematics, Practices

\section{Introduction}

Everyday Mathematics can be experienced. Mathematics which is continuously part of pedagogical strategies is likely to be free of culture, beliefs, and values. This notion holds that Mathematics can be taught in the absence of a common language because it is universal.

The idea of Ethnomathematics came as a broader view on how mathematics relates to the real world. Ethnomathematics can play a role in mathematical education, that those students belonging to a specific population, whether they are in mono or a multicultural society their vision, to better understand mathematics and may enrich their experience.

D'Ambrosio (1998), defines Mathematics as an intellectual instrument created by the human species to describe the real world and to help solve problems posed in everyday life. Mathematics is one subject that pervades life at any age and in any circumstance. The world has become increasingly globalized and competitive. In reality, mathematics teachers face difficult and challenging issues that surround more the diversity of learners. It suggests that the sociocultural background of every individual should be taken part in the learning process. Moreover, Article XIV of the 1987 Constitution of the Philippines mandates education to: 'encourage non-formal, informal, and indigenous learning systems as well as self-learning, independent, and out-of-school youth study programs, particularly those that respond to community needs. DepEd Order No. 62, s.2011, which is known as " Adopting the National Indigenous Peoples (IP) Education Policy Framework", further highlighted the country's commitment to achieving its Education for all (EFA) Advocacy. This is remarkable particularly in the policy statement No. 5, letter c, which is to provide adequate and culturally-appropriate learning resources and environment to IP learners" (Rubio, 2016). This shows that the teacher must be "glocal" in nature which means that teaching is not only globalized; it should also be localized.

Rubio (2016) also cited the study of D' Ambrosio, a Brazilian Mathematics educator who introduced ethnomathematics as the study of the local mathematics practices of specific cultural groups in the way of dealing with their environmental problems and everyday activities. The prefix "ethno" refers to identifiable cultural groups and includes their ideologies, languages, daily practices, and their specific ways of reasoning and inferring. The suffix 'tics' means the art or mathematical technique used by identifiable cultural groups in understanding, explaining, and managing problems and activities arising in their environment. The mathematics here means to explain, understand, and manage reality specifically by ciphering, counting, measuring, classifying, ordering, inferring, and modeling patterns arising in the environment. Ciphering is how writing the Eskaya numerical symbols while classifying is putting objects based on their common characteristic. Counting using the Eskaya numerals and modeling patterns were the geometrical shapes used in the tribe's daily routines. 
Furthermore, Ethnomathematics is a research program in the history and philosophy of Mathematics, with pedagogical implications, focusing on the arts and techniques of explaining, understanding, and coping with different sociocultural environments. It aims to contribute both to the understanding of culture and the understanding of Mathematics, and primarily to appreciate the beauty of Mathematics and culture.

One of the contexts of the $\mathrm{K}$ to 12 Basic Education Mathematics Curriculum other than belief and environment is the language and culture that include traditions and practices, as well as the learner's prior knowledge and experiences. Ulep (2014) also emphasized that $\mathrm{K}$ to 12 also enhances literacy through multilingualism which includes the age-context and culture-appropriate print and electronic texts in the Teachers' Guide. One of the teaching techniques in the $\mathrm{K}$ to 12 in which many subject areas and skills are organized and linked is to provide an integrative instructional program in the integration of local culture and indigenous resources (Dimaano, 2015).

Mathematics education should foster a greater understanding of how mathematics is applied in an increasingly technologically driven world. School mathematics needs to expand its parameter and become more inclusive of the mathematics formed in the world that the students inhabit (Avilla 2016). Mathematical education should include cultural issues which could help students in learning mathematics (Shaljan 2003).

Existing literature revealed that the field of ethnomathematics links students' diverse ways of knowing and learning through the use of embedded knowledge along with the academic mathematics curriculum. Rosa, M. \&Orey, D.C. (2011) highlighted that ethnomathematics approaches to the mathematics curriculum are intended to make school mathematics more relevant and meaningful for students and to promote the overall quality of their education. It helps to develop students' intellectual, social, emotional, and political learning by using their unique cultural referents to part their knowledge, skills, and attitudes.

The study on Indigenous Quantification Techniques of the Agta in Sierra Madre Mountains, the Philippines by Cadorna (2015) found out that the Agta's quantification system is unique and simple, anchored on their physical attributes, based on their immediate primary needs for survival, transmitted by their elders and associated on the availability of the natural resources. The indigenous quantification techniques were used in the formulation of IPs education curriculum and activities to preserve these from disappearance and to sustain cultural survival amidst technology development.

Ethnomathematics creates a learning environment which senses applicability and practicality in concrete situations. It amplifies the knowledge of the subject being studied and helps students to understand, explain and reflect upon their reality. (Shaljan, AM.,2003)

Rubio, (2016) explained in her study "that learning ethnomathematics is learning the applications of some mathematical concepts in real-life situations." To accept a concept or knowledge as well as its importance, the students must have a connection to it.

The results of this study serve as one of the bases in preparing instructional materials in teaching mathematics where this topic is integrated and emphasized in some particular lessons. As Rowlands and Carsons(2002) reflected in their critical review of ethno-mathematics, there were four possibilities considered in this area; (1) ethno-mathematics should replace academic Mathematics curriculum; (2) it should be supplemental to the Mathematics curriculum; (3) it should be used as a springboard for academic Mathematics; and finally, (4) it should be taken into consideration when preparing learning situation. Undeniably, ethno-mathematical studies aim to help the teacher establish cultural models of beliefs, thought, and behavior, the sense of contemplating not only the potential of the pedagogic work that takes into account the "knowledge" of the students but also the learning inside the school which is more meaningful and empowering ( D'Ambrosio (2001)).

On the other hand, even though different studies, vis-à-vis ethno-mathematics were done across the globe, the majority revealed that contextualized teaching and learning of the Mathematics Curriculum differ significantly in terms of understanding the concepts and ideas. A lot of studies on the same aspect were even tried here in the Philippines specifically in Jose Panganiban, Camarines Norte. However, teachers' receptiveness to the idea is still inadequate. This is due to the poor background on how to integrate Ethnomathematics in the teaching of Mathematics.

This motivated the researcher to study the Eskaya tribeto bridge the gap between the past and the future in the field of mathematics education and to illuminate the same field of study converging on the culture and local practices of the indigenous people of Tatay Duero, Bohol, particularly that of the Eskaya tribe. The focus of this study is to determine their ethno-mathematics practices in their daily lives and the inclusion of those practices in the teaching and learning of Mathematics from a cultural perspective.

The researcher envisioned that studying the tribe could create a great help to the Eskaya Tribe and to the province of Bohol, Philippines in general. This research would help the people of Eskaya in identifying and preserving their Ethno-mathematical cultural practices so that the students will respect the culture of the tribe and 
understand their mathematical roots. Also, it will contribute both to the understanding of culture and the understanding of Mathematics, and mainly lead to an appreciation of the unique Ethnomathematics culture of the tribe. Moreover, it will give ideas on how the Mathematics subject may be valued by students and even teachers by understanding its other side. This study will enhance and enrich one's vision and experience towards mathematics, helping everyone to better understand and learn the subject. Additionally, this will preserve the culture of Eskaya and most importantly the researcher hopes to integrate Ethnomathematics in the K-12 instruction.

The study's focus is to determine Ethnomathematics the Eskayas as practiced in their daily lives and its inclusion in the teaching and learning of Mathematics from a cultural perspective. Specifically, the study aimed to discover and document some of the socio-cultural characteristics of the Eskaya tribe.

\section{Materials and Methods}

To provide a complete picture of the study, the researcher used the qualitative method specifically the Ethnography that focused on the rich and thick description of the culture that includes the different culture components such as the ethnomathematical practices of the Eskaya tribe. The study isa kind of qualitative research which has its roots in cultural anthropology where researchers immerse themselves within a culture, and describe the values, beliefs, and practices of cultural groups (Camilar-Serrano, 2016).

The researcher utilized the Outline of Cultural Materials (OCM) Coding by (Bernard,2011; DeWalt \& DeWalt,2011; Murdock et al,2004). The OCM is usually used to interpret the ethnographic studies. It provides coding for the categories of social life that have traditionally been included in ethnographic descriptions like history, demography that deal with descriptions of cultural systems (DeWalt \& DeWalt,2011, p.184). The OCM coding is appropriate for ethnographic studies specifically it focuses on culture and includes the different components of Eskayaculture such as the ethnomathematical practices.

The study is about the Ethnomathematics of the Eskaya tribe specifically their ethnomathematical practices along with ciphering, simple counting, classifying, measuring, ordering, inferring, and modeling patterns arising from the environment. The way the school children use the learned ethnomathematics concepts in studying formal Mathematics is also described to unleash their culture and to develop instructional materials depicting the local practices of the tribe.

The study was conducted atTaytay, Duero, Bohol where the Eskaya tribe lives. The Eskaya tribe is an indigenous tribe found in the hinterlands of the towns of Duero, Guindulman, Pilar, and Sierra Bullones, Bohol's southeast interior. Likewise know as the "Visayan-Eskaya, "the community is only found in the island province of Bohol. They have a unique cultural heritage, a distinct language and literature, and traditional practices and arithmetic. Eventually, the group was recognized, and the community was awarded a Certificate of Ancestral Domain Claim (CADC) in 1996 and classified as an indigenous group under Republic Act or R.A. No.8371 entitled “The Indigenous People's Rights Act of 1997.

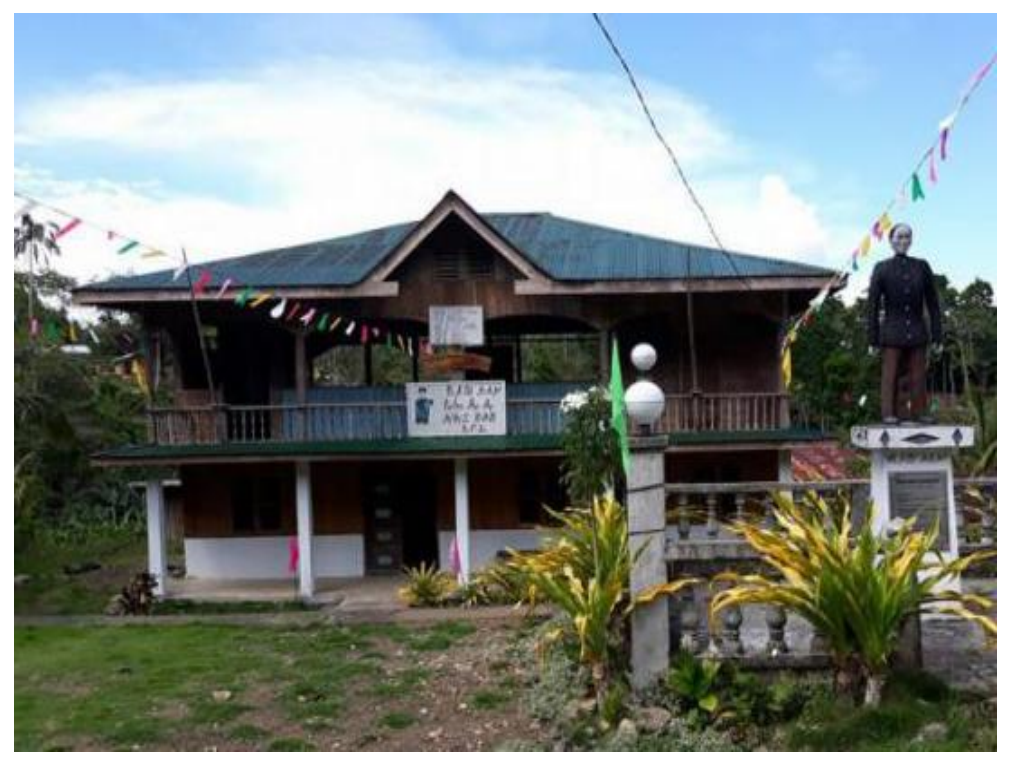

Plate 1:Eskaya Tribal School 
The Eskaya Tribal School is presented in Plate 1. The research participants were 5 "totoban" teachers, 5 “estowas' students, and 5 parents (sila / nima)of the Eskaya tribe. They were purposely selected and went through formal and informal interviews, observations, and focus group discussions in a natural context to make sense of a situation in the context of meaning. The researcher observed the daily activities of the people in Eskaya, ate with them, attended the tribal annual celebrations, and even stayed overnight or slept with them. The researcher attended the tribal Sunday mass and classes and lived and observed the day-to-day activities in the tribe.

The researcher used the purposive non-probability sampling technique which identifies a particular group of people, specifically the people in the Eskaya tribe. The researcher used data recording instruments such as paper and pencil, a video recorder, and other gadgets to capture the data needed. However, the researcher made sure that the interviewee was informed and asked permission before recording the information for ethical purposes through informed consent. Moreover, with regards to sensitive issues, some respondents may ask for privacy or anonymity.

The researcher employed a semi-structured interview guide. She also utilized Spradley's participant observation, as well as, ethnographic interview questions. These materials helped in collecting pertinent information which were examined and further led to the generation of themes.

The researcher asked permission from the chieftain of the Eskaya tribe and the Community Development Officerof the office of the NCIP of Tagbilaran City, Bohol, Philippines. The researchers made sure to respect the cultural practices and beliefs of the tribe.

The study attempted to illuminate the field of study covering the culture and local practices of the indigenous people of Taytay, Duero, Bohol, Philippines, particularly that of the Eskaya tribe. The analysis of data was done by identifying patterns, themes, or categories recurrent in the perceived data. The key themes or words of the study include ciphering, classifying, simple counting, ethno-mathematic, indigenous people, inferring, instructional materials, measuring, modeling pattern, and ordering. These terms were defined conceptually to make sure that there is a common understanding of the words. The extensive discussion was on how the Eskayatribe learns the ethno-mathematical concepts that they manifest in their daily lives. The way the schoolchildren use the learned ethno-mathematical concepts in studying formal Mathematics was also described to unleash their culture.

The significant data could not be collected all at once. The researcher needed to be in the field for 6-7months to capture the different events relative to the development of the study. All the observed details were done through field notes and subjected for interpretation. To confer its reliability and validity, triangulation, respondent feedback, and a series of consultations with the chieftain and (timama) teachers were done to arrive at the correct findings and conclusions about the data. These activities helped a lot to arrive at a good research output. The instructional materials depicting the local practices of the tribe were developed, as well as, an emergent theory on how the tribe learns mathematics.

\section{Results and Discussion}

Context is a locale, situation, or set of conditions of the Filipino learner that may influence his/her study and use of mathematics to develop critical thinking and problem-solving. Context refers to beliefs, environment, language, and culture that include traditions and practices, and learner's prior knowledge and experiences as stated in the twin goals of (DepEd Curriculum Guide,2011). Results showed that the ethnomathematical practices of the Eskaya tribe consist of the skills and techniques such as counting, measuring, ciphering, ordering, classifying and modeling pattern.

\section{Counting}

Every society needs to count. The Eskaya people can do simple counting by using their fingers. A numeration system is a way in which humans represent numbers. Aside from 46 Eskayaletters of the alphabet, the tribe has their Eskayaethnomathematical numeration system which is a simple counting but using their Eskaya dialect and symbol or script as shown in Tables 1 to 3 which the tribe used in their tribal Sunday class. 
$\ddagger$

Table 1: Eskaya Numeration System

\begin{tabular}{|c|c|c|}
\hline $\begin{array}{l}\text { The symbols learned } \\
\text { from formal school }\end{array}$ & $\begin{array}{c}\text { Counting in Eskaya } \\
\text { Dialect }\end{array}$ & $\begin{array}{c}\text { Eskaya ethnomathematical } \\
\text { symbol }\end{array}$ \\
\hline 0 & kwera & 2 \\
\hline 1 & $\mathrm{Oy}$ & $?$ \\
\hline 2 & Tre & 9 \\
\hline 3 & $\operatorname{coy}$ & 7 \\
\hline 4 & Pan & $\Gamma$ \\
\hline 5 & Sing & \\
\hline 6 & Nom & 7 \\
\hline 7 & Pin & $\pi$ \\
\hline 8 & Wal & 77 \\
\hline 9 & Sem & $\not 6$ \\
\hline 10 & Pon & $P_{1}$ \\
\hline 11 & Ponoy & $P P$ \\
\hline 12 & Pontre & $P g^{\circ}$ \\
\hline 13 & Poncoy & \\
\hline 14 & Ponpan & \\
\hline 15 & Ponsing & $P 4$ \\
\hline 16 & Ponnom & $P \sigma$ \\
\hline 17 & Ponpen & PH \\
\hline 18 & Ponwal & $2 \pi$ \\
\hline 19 & Ponsem & $P \mu$ \\
\hline 20 & Kaw & 92 \\
\hline
\end{tabular}

Table 2: Eshaya Numeration System cont

\begin{tabular}{|c|c|c|c|c|c|}
\hline $\begin{array}{l}\text { The symbols } \\
\text { learned from } \\
\text { formal school }\end{array}$ & $\begin{array}{c}\text { Counting in } \\
\text { Eskaya Dialect }\end{array}$ & $\begin{array}{c}\text { Eskaya } \\
\text { ethnomathe } \\
\text { matical } \\
\text { symbol } \\
\end{array}$ & $\begin{array}{l}\text { The aymbols } \\
\text { learned from } \\
\text { formal school }\end{array}$ & $\begin{array}{l}\text { Counting in } \\
\text { Eskaya } \\
\text { Dialect }\end{array}$ & $\begin{array}{c}\text { Eskaya } \\
\text { ethnomathe } \\
\text { matical } \\
\text { symbol }\end{array}$ \\
\hline 21 & Kaw-oy & $9 P$ & 41 & Panseoy & $F$ ? \\
\hline 22 & Kawtre & 99 & 41 & Pansetre & 53 \\
\hline 23 & Kawkoy & 97 & 43 & Pansekoy & $f 7$ \\
\hline 24 & Kawpan & if & 44 & Pansepan & FF \\
\hline 25 & Kawsing & 34 & 45 & Pansesing & $F 4$ \\
\hline 26 & Kawnom & $j \circ 7$ & 46 & Pansenom & $F 7$ \\
\hline 27 & Kawpen & jH & 47 & Pansepen & $\mathrm{FH}$ \\
\hline 28 & Kawwal & $j \phi$ & 48 & Pansewal & $F Q_{1}$ \\
\hline 29 & Kawsim & $3 \mu$ & 49 & Pansesim & $f^{\mu}$ \\
\hline 30 & Krat & 72 & 50 & Singpe & 48 \\
\hline 31 & Krat-oy & $7 ?$ & 51 & Singpeoy & $4+?$ \\
\hline 32 & Krattre & 79 & 52 & Singpetre & 49 \\
\hline 33 & Kratkoy & 77 & 53 & Singpekoy & 47 \\
\hline 34 & Kratpan & $7 F$ & 54 & Singpepan & $y_{i f}$ \\
\hline 35 & Kratsing & 74 & 55 & Singpesing & 244 \\
\hline 36 & Kratnom & $7 \%$ & 56 & Singpenom & y) 7 \\
\hline 37 & Kratpen & $7 / 4$ & 57 & Singpepen & $\mathrm{YH}_{\mathrm{H}}$ \\
\hline 38 & Kratwal & 74 & 58 & Singpewal & प्या के \\
\hline 39 & Kratsim & $7 \mu$ & 59 & Singpesim & $\mathrm{y}_{\mathrm{H}} \mathrm{H}$ \\
\hline 40 & Panse & $F 2$ & 60 & Nompe & 72 \\
\hline
\end{tabular}

Table 3:The Eskaya Numeration cont. 


\begin{tabular}{|c|c|c|c|c|c|}
\hline $\begin{array}{l}\text { The symbols } \\
\text { learned from } \\
\text { formal school }\end{array}$ & $\begin{array}{c}\text { Counting in } \\
\text { Eskaya Dialect }\end{array}$ & $\begin{array}{c}\text { Eskaya } \\
\text { ethnomathe } \\
\text { matical } \\
\text { symbol }\end{array}$ & $\begin{array}{l}\text { The symbols } \\
\text { learned from } \\
\text { formal school }\end{array}$ & $\begin{array}{c}\text { Counting in } \\
\text { Eskaya } \\
\text { Dialect }\end{array}$ & $\begin{array}{c}\text { Eskaya } \\
\text { ethnomathe } \\
\text { matical } \\
\text { symbol }\end{array}$ \\
\hline 61 & Nompeoy & $7 ?$ & 86 & Osnom & के of \\
\hline 62 & Nompetre & $7 j$ & 87 & Ospen & th 1 \\
\hline 63 & Nompekoy & +77 & 88 & Oswal & का क्र \\
\hline 64 & Nompepan & 가 & 89 & Ossem & $\nabla_{1}$ \\
\hline 65 & Nompesing & $7 y$ & 90 & Nor & \\
\hline 66 & Nompenom & 077 & 91 & Nor-oy & \\
\hline 67 & Nompepen & $7 \mathrm{FH}$ & 92 & Nortre & \\
\hline 68 & Nompewal & 우루 & 93 & Norkoy & F \\
\hline 69 & Nompesem & 가 $\mu$ & 94 & Norpan & \\
\hline 70 & Set & $H 2$ & 95 & Norsing & $P y$ \\
\hline 71 & Set-oy & $H ?$ & 96 & Nornom & 1 of \\
\hline 72 & Settre & $H g$ & 97 & Norpen & $r H$ \\
\hline 73 & Setkoy & 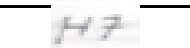 & 98 & Norwal & rọt \\
\hline 74 & Setpan & $H F$ & 99 & Norsem & \\
\hline 75 & Setsing & $\mathrm{H}_{4}$ & 100 & Oytos & \\
\hline 76 & Setnom & $H+2$ & 200 & Kawton & 328 \\
\hline 77 & Setpen & $\mathrm{HH}$ & 300 & Kraton & $7 \in 2$. \\
\hline 78 & Setwal & 4 क्ष & 400 & Panton & +28 \\
\hline 79 & Setsem & $H F$ & 500 & Sengton & $x 82$ \\
\hline 80 & Os & 712 & 600 & Nomton & 42.2 \\
\hline 81 & Os-oy & \%p & 700 & Penton & He8 \\
\hline 82 & Ostre & कै & 800 & Walton & ine \\
\hline 83 & Oskoy & 917 & 900 & Semton & HBE \\
\hline 84 & Ospan & $4 \%$ & 1000 & Man & 1228 \\
\hline 85 & Ossing & 714 & & & \\
\hline
\end{tabular}

The symbol can be extended by combining the Eskaya numbers. Like for example 1001 in Eskaya it is "oyman-oy", 1002 (oy-man-tre), 1003 (oy-man-koy), 1004(oy-man-pan), 1005 (oy-man-seng) and so on and so forth.

The tribe has their version of the four fundamental operations like addition (as), subtraction (ton), multiplication (bret), and division (pin) which the computations were similar to the usual mathematical computations. The symbols are shown in Table 4.

Table 4: Eskaya Tribe's Four Fundamental Operations

\begin{tabular}{lllc}
\hline Operation & Symbol & Eskaya Dialect & $\begin{array}{c}\text { Eskaya } \\
\text { Symbol }\end{array}$ \\
\hline Addition & + & as & 11 \\
Subtraction & - & ton & $\times$ \\
Multiplication & $\mathrm{x}$ & bret & $\%$ \\
Division & $\div$ & pin & - \\
\hline
\end{tabular}


The Eskaya tribe was taught on applying these symbols in computing. The concept of multiplication was used in doubling in computing the earning of income especially in selling vegetables and flowers, counting money, the concept of the division was used in equal sharing food for others through the idea of distribution; marking, and tallying during the tribe's election.

Moreover, the tribe has also identified their own name of the basic shapes name " liliyamor" like the "molyera" for circle, "pinla" for oval, "maldera" for rectangle and square and "lawde" for the triangle. As shown in table 5.

Table 5: Eskaya tribe's Basic Shape

\begin{tabular}{|c|c|c|}
\hline Basic Shape & lili ya mor & Symbol \\
\hline Circle & molyera & O \\
\hline Oval & pinla & $\longleftrightarrow$ \\
\hline Rectangle and square & maldira & $\square$ \\
\hline Triangle & lawde & $\triangle$ \\
\hline
\end{tabular}

\section{Measuring}

Every society needs to measure. The Eskaya people have their version of measuring time in terms of months and days like January(E-mi-o), February ( Hebi-o), March (Maso), April (Kabir), May ( Ma-o), June (Hubi), July (Hubi-on),August (Tatubi), September (Sitibi), October (Oktubi), November (Nobi) and December ( Dibi) as shown in Table 6.

Table 6: Eskaya version of Months

\begin{tabular}{ll}
\hline Month & In Eskaya \\
\hline January & E-mi-0 \\
February & Hebi-o \\
March & Maso \\
April & Kabir \\
May & Ma-0 \\
June & Hubi \\
July & Hubi-on \\
August & Tatubi \\
September & Sitibi \\
October & Oktubi \\
November & Nobi \\
December & Dibi \\
\hline
\end{tabular}

Similar to the ordinary days of the week, the Eskaya people have their version of days in a week such as Monday (Leni), Tuesday (Mimati), Wednesday ( Mibol), Thursday ( Hubir), Friday ( Bene), Saturday ( Sanubi) and Sunday as "Liongo" as shown in Table 7.

\begin{tabular}{ll} 
Table 7: Eskaya version of Days of the Week \\
\hline Day & Eskaya \\
\hline Monday & Len \\
Tuesday & Memate \\
Wednesday & Mebol \\
Thursday & Hube \\
Friday & Bene \\
Saturday & Sanobe \\
Sunday & Liyonggo \\
\hline
\end{tabular}

The local practices of the tribe in measuring show a stimulating connection in the field of ethnomathematics like for instance the elders would usually use the environment to determine the time through the placement of the 
sun or their shadow cast by objects. The Eskaya uses the sound produced by roosters early in the morning. The elder and mostly until now, they used their bare hands in measuring the rice to be cooked for her family. She also used her middle finger to measure the rice in cooking rice. An elder still used a "gantangan" and "salmonan" in measuring rice "magtakal". One "gantangan" is equivalent to 6 "salmonan" according to the Eskaya librarian.

Meanwhile, the elder carpenter said he used " sipilya" or "alapres" as planer and for making a corner in a door or decorative respectively as shown in Plate 2.

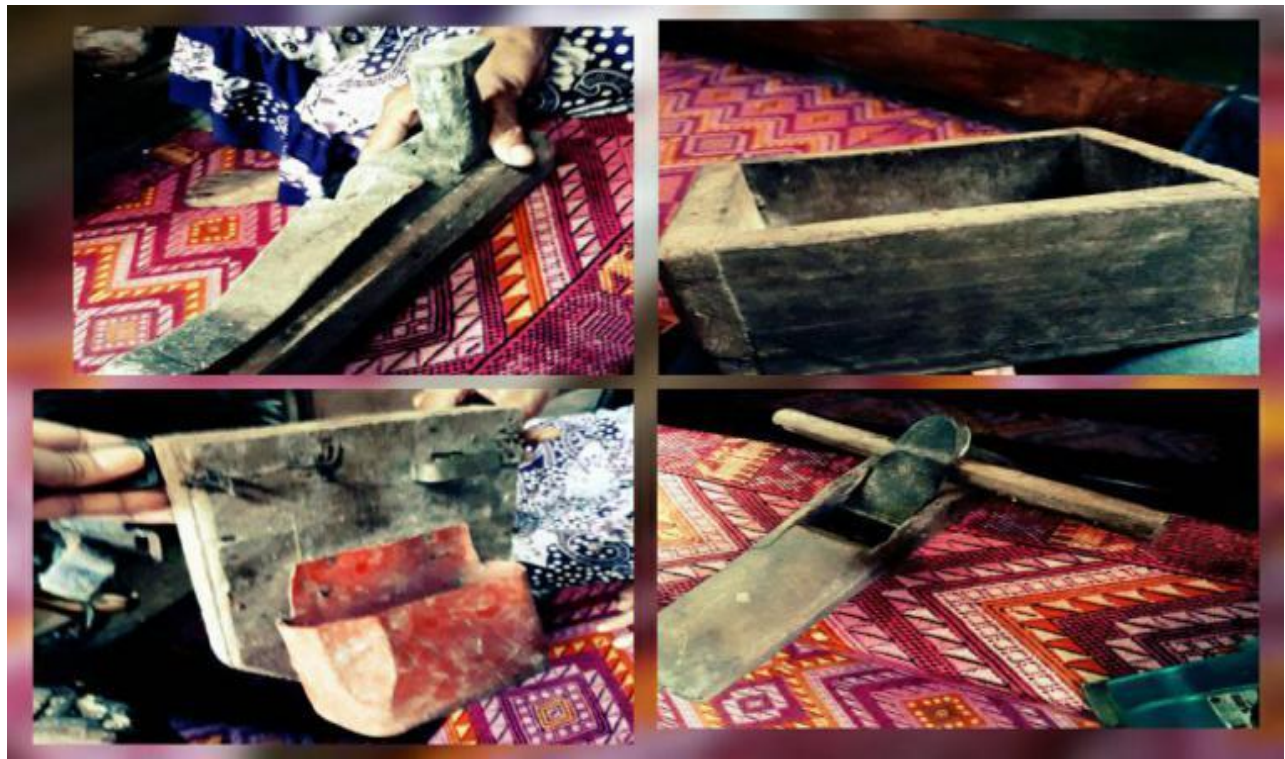

Plate2:The“alapresgantangan, sipilya"of the Eskaya

Another measurement happens when they sell their known "pangkabuhayan" products on the farm like vegetables and flowers with different prices like the famous strawberry is sold for P300 per 1 plastic bag, "sayote" for P10 per kilogram, Chinese cabbage P20 per kilogram, "petchay" P40 per kilo, "siliatsal" for P70 per kilo, "silihalang" for P100 per kilo, eggplant for P30 per kilo, "repolyo" for P30 per kilo, squash for P15 per kilo. Cucumber P40 per kilo, beans P40 per kilo, "sibuyas" P50 per kilo, ampalaya P40 per kilo, "kamatis" P300 per "kahon” or box, "gabi” P20 per kilo, cassava P15 per kilo and lettuce P100 per kilo.

The tribe has a "yakon" for P100 per kilo which according to "Naning" (an Eskaya elder) they believed "yakon" is a good anti-oxidant or body cleansing for long life.

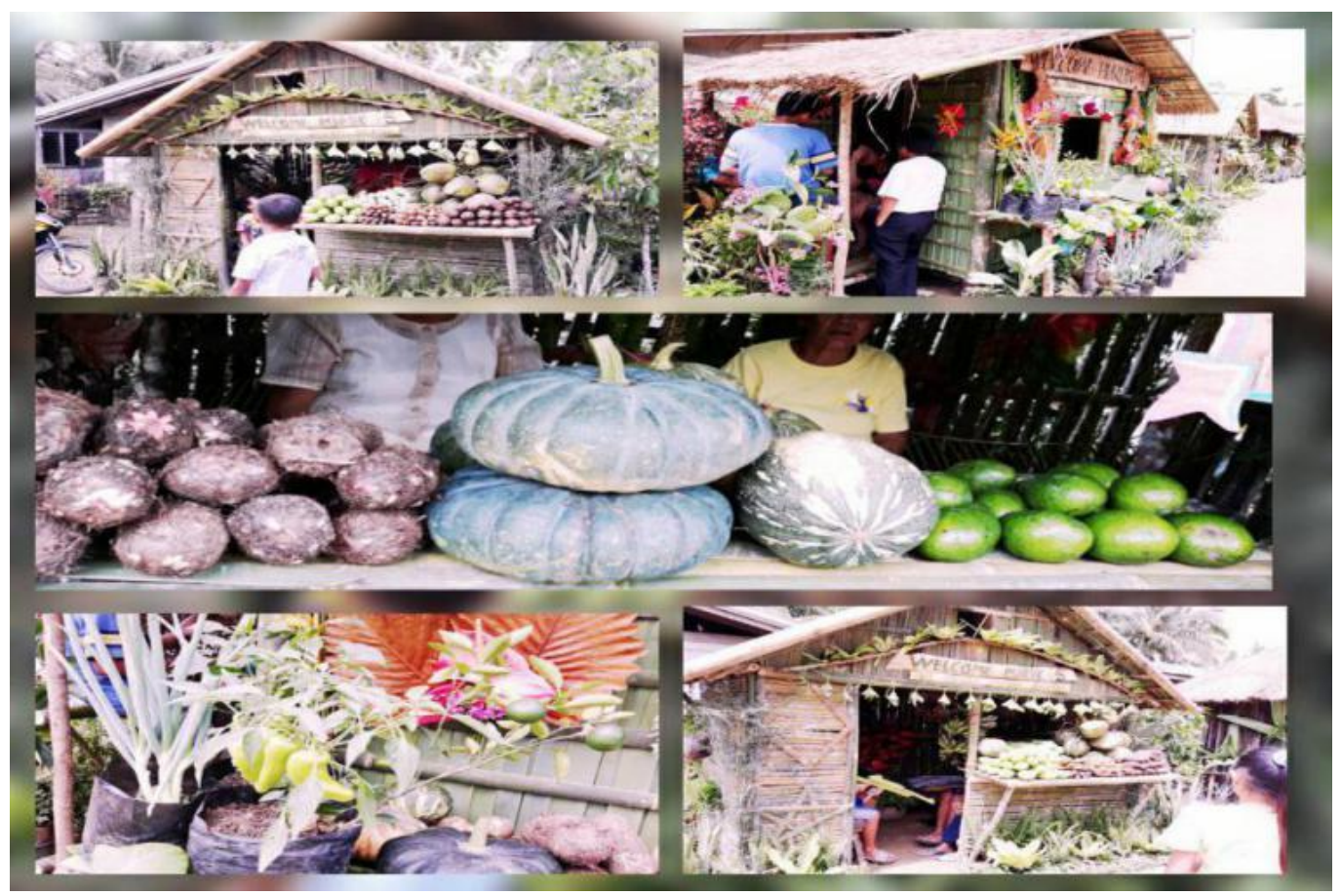

Plate 3: The Eskaya tribe's Agri products 
Every society has a design using patterns. Observing the ambience and terrain where the community settles can enrich one's mind in the real context of ethnomathematics. In this study, the patterns considered are produced by nature and the "manmade" creations by the tribe.

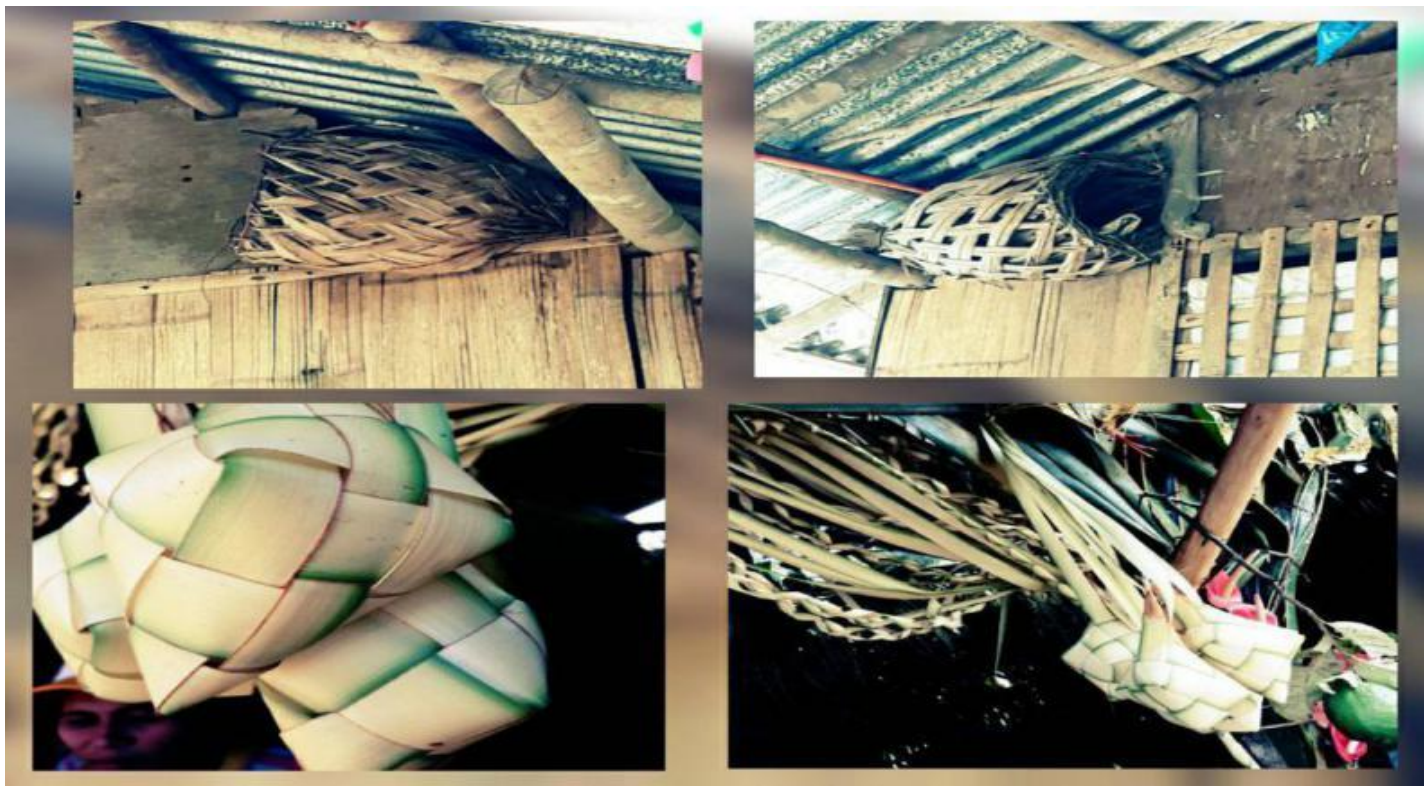

Plate 4: Eskaya Tribe's native "pugaran and poo-so"

An interesting activity of the tribe applying patterns is making a "poo-so" is rice wrapped and later boiled in a triangular casing made of woven coconut "lukay" and a native "pugaran" made of coconuts fronds which are used as shelters for an egg-laying hen. The tribe also uses patterns in making a design in a bamboo chair which could serve as a venue in appreciating the real-life context of Mathematics associated with tessellations in geometry.

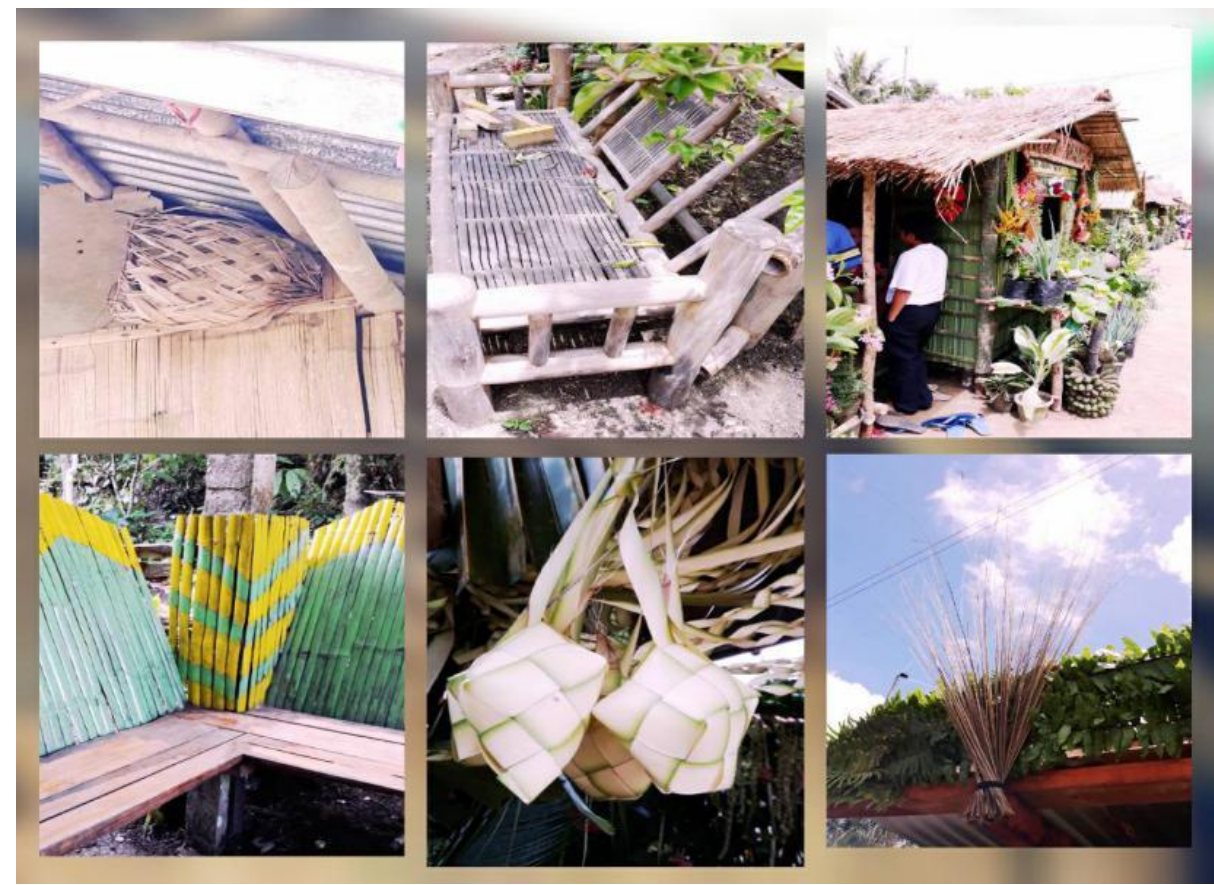

Plate 5:EskayaModeling Pattern

\section{Classifying}

Classifying is categorizing something according to a certain group or system based on certain characteristics. Classifying was observed in selling the flowers like the red anthurium was sold according to their sizes (small, medium, and large). Small is sold for P0.50 each, medium size for P0.75 and large sizes for P1.00 each, P5 for assorted for every 5 pieces. The "cedar" or a white anthurium was sold for P25 each. Notice that each activity involved ethnomathematics that guides them in doing their local routines. 


\section{Ordering}

Ordering is putting things into their correct place following some rules or reasons. Some of the stimulating local practices of the tribe can be observed through ordering. The researcher considers ordering as the arrangement or sequence of things and activities of the tribe following some rules or reasons. The common practices of planting among the Eskaya have significant ethnomathematical concepts an idea that can be seen in the followingactivities: making bamboo sticks to guard the plant, weighing the crops and vegetables, putting available organic fertilizer around the roots, harvesting the crops, vegetables, and flowers, selling poultry, livestock, and harvest to the local market among others.

\section{Ciphering}

Ciphering is the act of writing a code in which the letters of a text are replaced with others according to a system. This is somewhat, similar to the way the tribe does cipher. The activity involves signs, symbols, and human gestures which are other ways of conveying the message to their fellow "Eskayananons".

The ethnomathematics practices of the tribe along with ciphering were also observed through the activity like the sound produced by a " budjong" a shell used to inform the tribe of meetings or if a member of the family dies. The "budjong" is sounded 5 times to inform of a meeting and thrice if a member of the tribe dies.

\section{Inferring}

Applying inference in Mathematics is the act or process of deriving logical conclusions from premises known or assumed to be true. The laws of valid inference are studied in the field of logic. However, in this research inferring is used in the context of derived meanings from the observed information in the environment. Drawing inferences from the observed information is a basic human activity to interpret events in daily lives. In the case of Eskaya, when the events happen as a result of inferring, they become true for them, and eventually become part of the belief and culture.

Inferring is also observed in the local activities done by the Eskaya like for instance predicting the weather through the formation of the clouds, and inferring if a place is conducive for building a house. Another is following the type of moon in planting their crops like if the herbaceous vine crops they plant before a full moon, while non-vine herbaceous crops they plant after the full moon. Also, the Eskaya elders believe that if the sunsets' color is very red they believe that a calamity could happen. These are some situations that can be adapted to connect the lessons in Mathematics especially in the field of Statistics.

The contexts mentioned in this study in different activities of the tribe can be connected to Mathematics taught in school in several mathematical concepts like geometry, arithmetic, statistics, and algebra to make Mathematics more stimulating and meaningful on the part of the students. The relevance of ethno-mathematics is identified by connecting the concepts to their daily life activities. The ethnomathematical practices can be considered as the ethnomathematical skills that can be found in the Eskaya tribe as summarized in Figure 1.

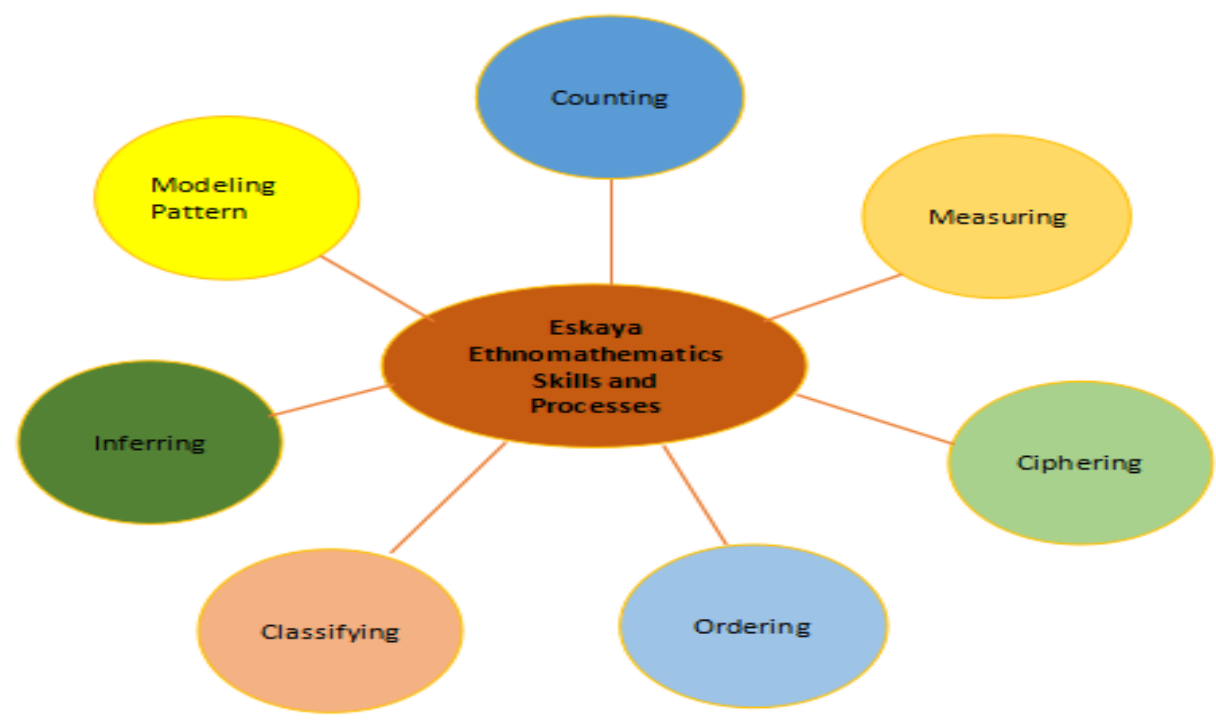

Figure1:The Eskayaethnomathematical skills and processes 


\section{Implications}

The ethnomathematical practices of the Eskaya tribe were found in their daily activities like gardening and farming. The way of life observed was mostly related to their culture and local practices. Their day of living was seen to be very simple in the rural area. What was very interesting with the tribe was their unique language, mathematical numeration, and writing system.

The ethnomathematical practices of the tribe that can be on their day-to-day activities like counting using the Eskaya numbers and numerals. They have other names for theEskayabasic shapes too.

The Eskaya still used some traditional methods of measuring. The tribal members classify the prices of flowers by sorting them according to sizes as small,medium, or large and some characteristics of the vegetables.Inferring was observed in the local activities done by the Eskaya, like observing the weather by looking at the sky and predicting an incoming calamity by looking at the color of the sunset. Clouds formation was used in planting crops, as well as observing the moon, and planting before a full moon. One tribal member said "I know a calamity is coming if the branches of trees fall even without a typhoonn.

The researcher was able to identify some vital contents of the EskayaEthnomathematics that was taughtto the Eskaya pupils. The contents of Ethnomathematics are: the numbers and number sense which includes the Eskaya numeration system such as the Eskaya numbersand numerals the Eskaya name of the basic shapes and the four fundamental operations; the measurement which includes the use of Eskaya numbers and measure to describe, understand and compare mathematical and concrete objectsin the tribe like the tribal name in measuring time, days, months.

\section{Recommendations}

The researcher recommends the continued preservation of the Eskaya culture through further research for the enhancement of the preservation program of EskayaEthnomathematics. This is to empower, appreciate, recognize, respect, and promote the Eskayaethnomathematical practices for the attainment of national unity and development. The researcher was hopeful for the integration of EskayaEthnomathematics to the $\mathrm{K}$ to 12 Curriculum of the Department of Education.

\section{Acknowledgements}

With sincere appreciation and gratitude, the researcher would like to thank Holy Name University administration, the NCIP Tagbilaran City, and the tribal leaders and chieftain of Taytay, Duero, Bohol, friends and family of the researcher.

\section{References}

S. Adam. Educational Studies in Mathematics, vo.52, no.3, 2003.

R. Bernard. Analyyzing Qualitative Data Systematic Approach 2nd ed., Saga Publication Inc., 2017.

U. D'Ambrosio. What is ethnomathematics, and how it can help.,2001

J. Rubio. The Ethnomathematics of the Kabihug Tribe in Jose Panganiban, Camarines Norte, Philippines. Malaysian Journal of Mathematical Sciences 10(s)., 2016.

D. Orey, M. Rosa. Cultural Assertions and Challenges towards Pedagogical Action of an Ethnomathematics. For the Learning of Mathematics, Vol.27, No.1, 2007

S. Rowlands, R. Carson. A Critical Review of Ethnomathematics. Educational Studies in Mathematics Vol.50, No.1 pp. (79-102).2002 